\title{
Intercultural approach to teaching Russian as a foreign language (on an example of Astrakhan State Medical University)
}

\author{
Alfiya Satretdinova and Zinaida Penskaya \\ State Medical University, 414000, Bakinskaya Str., 121, Astrakhan, Russia
}

\begin{abstract}
The article highlights some problems of multicultural education in Russia. The intercultural approach is considered in the context of teaching Russian as a foreign language. The work offers various forms of intercultural education. The structure of a training textbook with a multimedia application for foreign students "Welcome to Astrakhan!" is presented. In addition, the authors offer their own experience in organizing and conducting extracurricular activities, in particular an international forum of students "Be with us! Speak Russian!» on the basis of the Astrakhan State Medical University in which more than 6000 students from 32 regions of the Russian Federation and about 2000 students from 56 countries of the near and far abroad are annually studied. The University provides training in three languages (Russian, English, and French) aimed at improving communication skills and developing intercultural competence. The study revealed that extracurricular activities increase students' interest in Russian and contribute to the harmonization of relations between students in a group. Social significance of the presented projects is to create a positive image of the Astrakhan region and the Russian Federation as a whole abroad, as well as, to strengthen a position of Astrakhan universities in the international market.
\end{abstract}

\section{Introduction}

The problem of multicultural education is particularly relevant and complex in the multiethnic Russian society. In connection with the global integration processes that cover all spheres of modern society and with the growing academic mobility in higher education the formation of a culture of tolerance and civic identity in a multicultural society is becoming a priority area of training and upbringing activity of higher education. [1]

This direction is especially relevant at the present time as representatives of more than 140 nationalities live and 37 national and cultural public associations operate in the Astrakhan region. Every year a number of foreign students who want to get an education in Astrakhan universities increases.

The Federal State Budgetary Educational Institution of Higher Education "Astrakhan State Medical University" of the Ministry of Health of the Russian Federation is a large educational and scientific institution of the Caspian macroregion which has the necessary human resources, a powerful scientific and material-technical base. The strategic purposes 
are to increase the competitiveness of the University in a domestic and international scientific and educational environment, to integrate into an innovative development of the region and the Russian Federation, to enter an international educational space.

The development of relations between the people of Russia, as well as, with other people of the world, determines the purposes and content of upbringing a culture of interethnic communication among students. This task is clearly defined in the Strategy of the state national policy of the Russian Federation for the period up to 2025. This document emphasizes significance of developing youth people at all stages of the educational process an all-Russian civic identity, patriotism, civic responsibility, a sense of pride of the history of Russia, and fostering culture of interethnic communication based on respect honor and national dignity of citizens, traditional Russian spiritual and moral values; preserve and support Russian as a state language of the Russian Federation and the people of the Russian Federation; form a system of social and cultural adaptation of foreign citizens in the Russian Federation and their integration into Russian society. [2]

Annually more than 6000 students from 32 regions of the Russian Federation and about 2000 students from 56 countries of the near and far abroad are educated in Astrakhan Medical University. Astrakhan SMU (State Medical University) has created conditions for promoting the consolidation of various layers of civil society, reducing social tension between representatives of various faiths and national cultures. [3, 4] The department of Russian of Astrakhan Medical University makes a great contribution to this work. For many years the teachers of the department of Russian has successfully cooperated with the departments of Russian, literature, pedagogy and psychology, the preparatory department for foreign citizens of ASU (Astrakhan State University) implementing joint educational, scientific, cultural-educational projects. Foreign students and students of the preparatory department of Astrakhan State Medical University have repeatedly won student Olympiads, quizzes and competitions held at the Astrakhan State University. The department of Russian of Astrakhan State Medical University organizes some scientific and practical conferences, seminars, forums: inter-university methodological seminar "Professional Education of Foreign Students in Russian" (2012), Internet conference with international participation "Traditions and Innovations in Teaching Russian and Speech Culture in Higher School" (2013), scientific-practical conference with international participation dedicated to the $100^{\text {th }}$ anniversary of the Astrakhan State Medical University "Actual Problems of Teaching Foreign Students in a Medical University" (2018), interuniversity scientific-practical conference of students and young scientists with international participation "Problems of Tolerance and Cultural Integration in a Multicultural Educational Environment of a Russian University" (2019), interregional scientific-practical online-conference "Opportunities and Prospects of Teaching Russian as a Foreign Language" (2020).

In connection with the global integration processes that cover all spheres of modern society and the growing academic mobility in a higher education, intercultural education is becoming a priority - "an individual process of personal development that leads to change in behavior of individual associated with understanding and accepting culturally specific forms of behavior of representatives of other cultures». [5]

A purpose of multicultural education is to form a person with a developed sense of understanding and respect for other cultures and an ability to live in peace and harmony with people of different nationalities, races, and beliefs. A person is capable of active and effective vital activity in a multi-ethnic and multicultural environment. [6] 


\section{Materials and Methods}

In the research process we use some general theoretical methods: analysis of psychological, pedagogical, and methodical literature (A. N. Dzhurinsky, O. A. Bashkina, E. Yu. Gagarina, A. Kh. Akhmineeva, A. S. Krasovskaya, I. S. Kon, V. V. Makaev, Z. A. Malkova, L. L. Suprunova, I. A. Agafonova, O.V. Ivanchuk, R.V. Zabirov, A. Kh. Satretdinova, Z.P. Penskaya, and others), analysis of experience of many years in bilingual teaching of foreign students at Astrakhan State Medical University.

\section{Results and discussion}

Extracurricular activities are particularly popular among forms of intercultural education. The department of Russian of Astrakhan State Medical University is a venue for an annual cultural and educational campaign "A Big Ethnographic Dictation", an initiator and organizer of various student events (festivals, competitions, Olympiads) aimed at popularizing and promoting Russian.

For many years on the basis of the department of Russian of Astrakhan State Medical University a circle of Russian literature lovers and an educational linguistic center operate. Their activities are aimed at increasing interest of students in studying Russian and culture of Russia, and developing communicative competence for future doctors. Annually teachers of the department of Russian organize events aimed at successful adaptation of foreign students to the conditions of living and studying in Astrakhan, upbringing their tolerant attitude to other peoples and their traditions (a week of Russian, a contest of Russian songs, an international festival of arts for foreign students, quizzes, Olympiads, forums, student conferences for the day of Slavic writing and culture, a day of Russian, a day of independence of Russia, etc.).

In addition, a training textbook with a multimedia application for foreign students "Welcome to Astrakhan!" was developed by teachers of the department of Russian. The purpose of this training textbook is to form a linguistic local-history competence based on the historical and cultural space of Astrakhan. The textbook is designed with some features of teaching Russian as a foreign language in the first year. They are complex formation of speech skills, interrelated training in phonetics, vocabulary, grammar, and all types of speech activity, the intensity of training.

The textbook is relevant because it is very important for forming a linguistic localhistory competence to fulfilment of the communicative requirements of students from near and far abroad countries. In the modern educational process conditions when a degree of self-dependence of students is rising, a reference-type textbook plays an important role. Using this textbook students can self-dependent search for information and acquire it. The textbook with multimedia provide consistency, visualization, and complexity in the description of the historical and cultural sphere of Astrakhan. This textbook is built on the basis of methodically well-founded introduction of vocabulary with regional and cultural semantics, as well as, self-dependence in acquiring the linguistic local-history material. When working out such textbook of a new type the achievements of information and telecommunications technologies are used: multimedia technologies, Internet technologies. The training textbook with multimedia is a reference book in three languages. It is a system of electronic presentations and video files. The training textbook with multimedia is based on some principles.

1. Store a large volume and diverse content of training material by a computer form of presentation, quickly update and supplement it, reduce time of information search in the textbook, semanticize vocabulary by a system of hyperlinks and multimedia tools, Internet resources expand the information capabilities of the textbook, etc. 
2. The multicomponent of a training model of representations of Astrakhan is presented by logical connections, hierarchical organization, and lexical means. The system of linguistic local-history units according to the thematic sign makes the textbook active. It allow to model future speech work of foreign students, i.e. to orient the spheres of speech work, to determine the fundamental topics and situations according to the learning purposes.

4. The possibilities of traditional visualization (drawings, photographs) are expanded by using multimedia tools (illustrations of graphic images, photos, videos, animations, audio materials). Video materials (songs, audio recordings of poems, fragments of feature films, documentaries, TV shows) from the Internet are used.

The structure of the training textbook includes a review film "Astrakhan is a Caspian capital", 5 thematic blocks, articles (the Ancient city of Astrakhan, Astrakhan is an industrial center, Cultural capital, Educational center, Famous Astrakhan residents), an alphabetical glossary in three languages (Russian, English, French).

Each text is accompanied by a dictionary entry presented as a text and audio file. The entry describes some basic characteristics value of a linguistic local-history unit (for example, the location and function data of objects, professions, famous and prominent people, significance in a historical-cultural sphere of a city), grammar, geography of region, the etymology of some objects name, the most well-known facts of the realities linguistic local-history unit in literature, music, fine arts, etc.

Dictionary entries include anthroponyms (names of writers, poets, artists, actors, sportsmen, musicians, doctors); toponyms (geographical names); ergonyms (names of institutions, enterprises); dates.

The first lesson develops the ability to understand a text of socio-cultural topics by ear (the text "Cultural Capital") and use the received data to build your own oral expression. The second and third lessons are aimed to form some skills of building their own expression by the data of their own reading (home reading entries and preparing oral expression), to receive some data by ear (20 students' reports), interpret, and use listened data, make their oral and written expression (report, filling a training matrix, interview, work with map, do excursion, write letters). To get ready for these lessons, students do selfdependent homework about the sights of a city, some famous people of Astrakhan with some materials of a textbook with multimedia.

Sample tasks: choose the keywords and phrases necessary to describe the proposed regional and cultural units; develop a program for a two-day stay to your friend in your city with a detailed plan of the intended objects of attendance.

Doing this task students examine places of cultural and historical significance and objects with household functions. They are the Kremlin, museums, theatres, Cathedrals, embankments, clubs, restaurants, parks, etc.). To make the dialogue between a tourist and a resident of a city, to prepare and conduct an excursion in a city (make some questions, little texts about interesting places), write a letter to a friend.

Practical significance and relevance of this textbook is its versatility allowing to use its materials in the process of studying Russian by foreign students in many forms. They are class work (fragmented use), the out-of-class one (some excursions, meetings of Russian literature lovers club, supervisor hours, Olympiads, competitions, and etc.), the selfdependent one (doing homework, acquaintance with historical-cultural space of a city), the remote one (individual programmes). Variety of using the total volume linguistic localhistory material is made by reference form of construction textbook. Its introduction in a training process at the initial stage of training depends on the purposes and objectives of study, as well as, foreign students interests and needs.

Work on the project included 4 stages. They are 1) development of a theoretical basis for creating the manual; 2) definition of its structure and thematic content, lexical 
composition on a basis of a linguistic local-history minimum; 3) substantiation of a structure of a dictionary entry, methods of semantics of linguistic local-history units; 4) development of techniques for working with the multimedia manual "Welcome to Astrakhan!".

Using the multimedia manual "Welcome to Astrakhan!" contributes to the better mastering regional and cultural background knowledge, their using in writing your own texts, i.e. the effective formation of communicative competence.

At Astrakhan State Medical University training is conducted in three languages (Russian, English, and French). At the initial stage of training Russian and foreign students do not communicate due to the language barrier. In this regard, the project of the international student forum "Be with us! Speak Russian!" which is aimed at the language interaction of students from Russia, countries of near and far abroad is developed. Realization of this forum is aimed at successful socio-cultural and psychological adaptation of foreign students $[7,8]$, their comfortable entry into a new language and educational environment, and the formation of a tolerant attitude to representatives of different cultures and ethnic groups.

The purpose of this project is to popularize Russian and promote it in the world cultural space. The social significance of this project is to strengthen a position of Astrakhan Medical University in the international market of the educational services and to create a positive image of the Astrakhan region and the Russian Federation as a whole abroad.

This project is aimed at successful language interaction of students from Russia and countries of near and far abroad; realization of the creative potential of students. The proposed project increases interest of students in learning Russian and culture of Russia [9], promotes international relations and attracts more foreign students to universities of Astrakhan.

Implementation of the project of International Student Forum "Be with us! Speak Russian!" contributes to the successful socio-cultural and psychological adaptation of foreign students studying in Astrakhan universities, their comfortable entry into a new educational environment, and the formation of a tolerant attitude among young people to representatives of different cultures and ethnic groups. The forum is also due to the need to preserve Russian and strengthen its status as a language of international communication.

\section{Conclusions}

1. Intercultural education is focused on the formation of communicative and intercultural competencies, upbringing a tolerant language personality of a modern student in a multicultural space, expansion of interpersonal contacts with representatives of other cultures, and harmonization of a process of self-identification of an individual.

2. Participation of foreign students in extracurricular activities provides real communication practice, increases their interest in learning Russian and culture of Russia, contributes to the socio-cultural and psychological adaptation of foreign students studying in Astrakhan universities, their comfortable entry into a new educational environment, and the formation of a tolerant attitude among young people to representatives of different cultures and ethnic groups.

3. Extracurricular activities are necessary to preserve Russian and strengthen its status as a language of international communication.

4. Successful language interaction of students from Russia, near and far abroad is aimed at developing international relations and attracting more foreign students to Astrakhan universities. 


\section{References}

1. A. N. Dzhurinsky, Concepts and Realities of Multicultural Education, 304 (2008)

2. Strategy of the State National Policy of the Russian Federation for the period up to 2025 (2012)

3. O. A. Bashkina, Act. Prob. of Train. For. St. at a Med. Univ., 11(2018).

4. E.Yu. Gagarina, A.Kh. Akhmineeva, A.S. Krasovskaya, Psych. and ped. supp. of univ. stud. in the mod. socio-cult. sp., 72(2018).

5. I. S. Kon, To the problem of national character, 122 (1971)

6. V. V. Makaev, Z. A. Malkova, L. L. Suprunova, Pedag., 4, 3(1999)

7. I. A. Agafonova, O.V. Ivanchuk, Rev. Dil. Cont.: Educ., Pol. y Val. (2019)

8. O.V. Ivanchuk, R.V. Zabirov, Rev. Dil. Cont.: Educ., Pol. y Val. (2019)

9. A. Kh. Satretdinova, Z. P. Penskaya, Rev. Dil. Cont.: Educ., Pol. y Val., 21 (2019) 